\title{
Effect of different doses of creatine on the bone in thirty days of supplementation in mice: FT-Raman study
}

\author{
Humberto Miranda ${ }^{\mathrm{a}, \mathrm{b}, *}$, Renato Aparecido de Souza ${ }^{\mathrm{a}}$, Maira Gaspar Tosato ${ }^{\mathrm{c}}$, \\ Roberto Simão ${ }^{\mathrm{b}}$, Murilo Xavier Oliveira ${ }^{\mathrm{a}}$, Flávia Mafra de Lima ${ }^{\mathrm{a}}$, Erika Ferrari ${ }^{\mathrm{a}}$, \\ Wellington Ribeiro ${ }^{\mathrm{a}}$, Leonardo Marmo Moreira ${ }^{\mathrm{d}}$ and Airton Abrahão Martin ${ }^{\mathrm{c}}$ \\ ${ }^{a}$ Laboratory of Physiology and Pharmacodynamics, Institute of Research and Development, \\ Universidade do Vale do Paraíba, São José dos Campos, SP, Brazil \\ ${ }^{\mathrm{b}}$ School of Physical Education and Sports, Universidade Federal do Rio de Janeiro, Rio de Janeiro, RJ, \\ Brazil \\ ${ }^{\mathrm{c}}$ Laboratory of Biomedical Vibrational Spectroscopy, Institute of Research and Development, \\ Universidade do Vale do Paraíba, São José dos Campos, SP, Brazil \\ ${ }^{\mathrm{d}}$ Departamento de Engenharia de Biossistemas, Universidade Federal de São João Del Rei, São João \\ Del Rei, Minas Gerais, Brazil
}

\begin{abstract}
In this study, Raman spectroscopy was employed in order to provide information about the effects of different doses of creatine on bone tissue composition of phosphate apatite $\left(960 \mathrm{~cm}^{-1}\right)$, carbonate apatite $\left(1170 \mathrm{~cm}^{-1}\right)$ representing the mineral content and collagen matrix (amide I, $1665 \mathrm{~cm}^{-1}$ ). The animals (27 Balb-C male) were divided into three groups ( $n=9$ per group): control (CON), supplemented with $0.5 \mathrm{~g} / \mathrm{kg}(\mathrm{Cre}-0.5)$ and with $2.0 \mathrm{~g} / \mathrm{kg}(\mathrm{Cre}-2.0)$ creatine. The experiment was carried out for thirty days. After this time, the right femur of each animal was harvested. The specimens were assessment by FT-Raman spectroscopy and in a total of 81 spectra were acquired in the medial diaphysis of the femur. The Raman data strongly suggest that only the creatine supplementation of $0.5 \mathrm{~g} / \mathrm{kg}$ effective to the bone constitution. Furthermore, the present results demonstrate that creatine ingestion provokes decrease in the relative presence of carbonate in the chemical constitution of bones. The decrease in the carbonate content can be associated to a significantly bone resistance altered to several mammalians. The analysis evidenced that the mineral concentrations in the Raman spectroscopy could be a feasible method for non-invasive or minimally invasive assessment of bone tissue composition. Probably this high sensitivity can be employed to determine spectral profiles, such as wavelength of maximum absorption and maximum intensity of absorption of each wavelength, of several bone diseases.
\end{abstract}

Keywords: FT-Raman spectroscopy, femur, bone quality, creatine, nutrition supplement

\section{Introduction}

Several athletes and physical activity practitioners, have used creatine (Cr) (Fig. 1) supplementation because of a number of benefits that it can bring. Creatine (Cr) was identified in 1832 by Michel Eugene

\footnotetext{
* Corresponding author: Humberto Miranda, Institute of Research and Development (IP\&D), Universidade do Vale do Paraíba (UNIVAP), Av. Shishima Hifumi, Urbanova, 2911, São José dos Campos, SP 12244-000, Brazil. Tel.: +55 1239471124 ; E-mail: humbertomiranda01@gmail.com.
} 


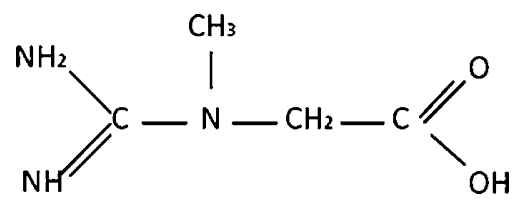

Fig. 1. Schematic representation of the chemical structure of creatine.

Chevreul, who discovered that this organic compound is a relevant component of the skeletal muscle. The name "creatine" is be associated to the Greek word that means flesh, i.e., Kreas. Creatine $(\mathrm{Cr})$ supplementation became a popular ergogenic aid to increase exercise performance. Studies have shown several benefits of creatine supplementation, such as increased muscle power [15,34], increased fat-free mass [2,23,31] and increase strength in healthy subjects [29]. The benefits of $\mathrm{Cr}$ supplementation on exercise performance have been extended as a possible therapeutic agent in the treatment of disease conditions [16].

Creatine (Cr) (Fig. 1) is a non-essential dietary element occurring naturally in the human body and is partly synthesized by the kidney, pancreas and liver (approximately 1-2 g per day), and partly ingested with food (approximately 1-5 g per day), especially with meat and fish [38]. In humans, about half of the daily creatine is biosynthesized from three different aminoacids (arginine, glycine and methionine), being that the rest is taken in by alimentary sources. $\mathrm{Cr}$ is distributed throughout the body with $95 \%$ of $\mathrm{Cr}$ found in skeletal muscle [12]. Consequently, the $\mathrm{Cr}$ research has focused primarily on its effects on skeletal muscle, which plays an important role in rapid energy provision during muscle contraction regenerating ATP through a reversible reaction catalyzed by creatine kinase (CK) [37].

For the development and repair process of bone, osteoblasts require high energetic demand to survive, proliferate, differentiate and synthesize the extracellular matrix. Evidence suggests that the Cr-CK system also plays an energetic role in this tissue [11]. Further corroborating evidence for the importance of CK in skeleton formation is that high CK activity is noted in chondrocytes [14,17]. Moreover, it has been noted that CK activity is also required for the development of endochondral bone and is a key enzyme in the cellular energy metabolism of osteoblasts [9]. Ch'ng and Ibrahim [4] demonstrated those periods of increased energy demands in osteoblasts leaded to upregulated CK expression and allowed changes in cell shape and adherence of osteoblasts cells to bone surfaces. Likewise, it is tempting to speculate whether Cr supplementation could be used as promoter of improved bone quality. Recently, Antolic et al. [1] verified the influence of supplementation with $\mathrm{Cr}$ monohydrate on bone structure and function in growing rats during 8 weeks, to establish a therapeutic model. Bone mineral density (BMD) and content (BMC) femoral were assessed using dual-energy X-ray absorptiometry (DEXA) at the beginning and end of the protocol and it was demonstrated that the CR-treated rats presented greater lumbar BMD and femoral bending load at failure compared with the control group rats $(p<0.05)$. However, more studies are need to determine the influence of $\mathrm{Cr}$ supplementation in the biochemical composition of bones.

Raman spectroscopy is an optical tool which could permit precise information on the chemical composition of organic and inorganic samples, allowing less invasive and non-destructive qualitative and quantitative analysis [5,13]. This great potential has motivated several biological and biomedical applications of Raman spectroscopy in order to obtain biochemical characterization and diagnosis of several diseases [24]. In fact, the clinical process to assess pathological changes in tissue is currently related to the histopathology. However, the management of biopsy material and the interpretation of the respective analysis are not trivial. The clinical characterization based on these analyses could lead to diagnostic delay and to the possibility of taking an unrepresentative sample. Furthermore, this clinical procedure presents high cost and provokes significant patient trauma [33]. Actually, biological samples present 
significant issues to be addressed, which are associated to their heterogeneous characteristics. Besides, most components are present in low physiological concentration in body fluids (in order of $\mathrm{mmol} / \mathrm{l}$ to $\mathrm{nmol} / \mathrm{l}$ ) [30]. In spite of these difficulties, several spectroscopy techniques have been considered as basis for minimally invasive and non-destructive measuring systems [41].

In this context, Raman spectroscopy has been considered effective to assess sample information at the molecular level, and has been used on several minimally and non-invasive diagnostic applications of biological samples such as detecting toxicity of different doses of a pollutant on bacterium media [6] atherosclerosis in coronary and carotid arteries [25,32], human basocellular skin cancer [26], lactate identification in blood [27], osteoinduction in biomaterial implants [40], several bone diseases [3], bone synthesis and osteointegration after healing [20,21], and evaluating the microstructure of human cortical bone (osteon) [35]. Thus, Raman spectroscopy has been accepted by many authors as a viable tool for the study of bone mineralization $[7,39]$ and emerges as an important complement to traditional methods for detection, quantification and imaging of local variations in the molecular structures of bone matrix and mineral [3].

Several works have proposed the use of Raman spectroscopy to obtain the mineralization and organic matrix to assess the bone quality $[3,7,28,39]$. At least two different aspects of the mineral component of bone affect its mechanical properties: the degree of remodeling and bone mineral density (mineral to matrix phases ratio) and the degree of crystallinity of the mineral content (related to mineral quality and carbonate/phosphate ratio) $[3,8]$. The chemical composition of bone tissue could be assessment by the ratios between spectral Raman bands of interest, i.e., femoral trabecular bone had a higher mineral/matrix ratio in fractured rather than in unfractured women, while iliac crest biopsies revealed a higher carbonate/phosphate ratio in cortical bone from woman who had sustained a fracture [22]. Also, bones from postmenopausal osteoporotic patients found a lower mineral/matrix ratio and higher carbonate/phosphate ratio when compared with normal patients [10]. The crystallinity, an important bone quality factor, could be associated with carbonate/phosphate ratio and indicates the extent of carbonate incorporation in the hydroxiapatite lattice [39].

Although there are many articles focuses in bone study by spectroscopy, from our best acknowledgment the study of the effect of supplement in the bone are rare. Therefore, the aim of this study was to use near-infrared FT-Raman spectroscopy to evaluate the bone tissue composition in creatine supplemented mice.

\section{Material and methods}

\subsection{Experimental model}

Twenty-seven male Balb-C, young adult mice (12 week old), were obtained from the bioterium of Campinas University (CEMIB-UNICAMP - Campinas, SP, Brazil). The mice were kept in plastic cages (10 animals/cage) in the bioterium of the Physiology and Pharmacodynamics Laboratory of the Research and Development Institute of the University of the Vale do Paraíba (São José dos Campos, SP, Brazil) with controlled temperature $\left(22-24^{\circ} \mathrm{C}\right)$, relative humidity $(40-60 \%)$ and photoperiod $(12 \mathrm{~h}$ light-dark cycle). The rats were acclimatized to the facility, cage and standard rodent diet for two weeks before to the initiation of the experimental interventions. Moreover, all the animals had access to palletized food (Purina ${ }^{\circledR}$ lab chow) and water ad libitum. After four weeks the animals were randomized into one of three experimental groups ( $n=9$ per group): control group $(\mathrm{CON})$, supplemented with creatine $0.5 \mathrm{~g} / \mathrm{kg}$ 
group (Cre-0.5) and supplemented with creatine $2.0 \mathrm{~g} / \mathrm{kg}$ group (Cre-2.0). All the procedures adopted in this study were according to the laboratory animals handling and care principles recommended by the COBEA (Brazilian School of Animal Experimentation) and approved by the Ethics in Research Committee of UNIVAP (Protocol \# A088/CEP/2007).

\subsection{Bone samples}

At aged of 18 weeks all animals were anesthetized by intramuscular administration of Xylazine $(40 \mathrm{mg} / \mathrm{kg})$ and Ketamine $(50 \mathrm{mg} / \mathrm{kg})$ and euthanized by intracardiac administration of $\mathrm{KCl}$ solution $(10 \%)$. The right femur was harvested. All soft tissues were removed from the bones. The bones were identified snap frozen and stored in liquid nitrogen $(77 \mathrm{~K})$ in cryogenic vials $\left(\right.$ Nalgene $\left.{ }^{\circledR}\right)$. Before the FTRaman spectroscopy, samples were warmed up to room temperature with $0.9 \%$ physiological solution.

\subsection{FT-Raman system}

The FT-Raman spectrometer (RFS 100/S ${ }^{\circledR}$ - Bruker Inc., Karlsruhe, Germany) with a germanium detector cooled by liquid nitrogen was used to collect the data. The samples were excited by an air cooled Nd:YAG laser $(\lambda=1064.1 \mathrm{~nm})$. The power of the Nd:YAG laser incident at the sample was $250 \mathrm{~mW}$. The spectral resolution was set to $4 \mathrm{~cm}^{-1}$ and for each specimen three different region were analyzed with 300 scans totalizing 27 spectra per group. Before the spectra treatment, the average of the three spectra per specimen for each period were performed, resulting into 81 spectra. For the qualitative and semi-quantitative spectral analysis, the average spectra were baseline corrected and then normalized to the $960 \mathrm{~cm}^{-1}$ peak $[18,19,36]$. The changes of organic and inorganic enamel components were analyzed by comparing the integrated areas of the Raman peaks centered at $960 \mathrm{~cm}^{-1}$ (p1), $1071 \mathrm{~cm}^{-1}$ (p2), to the peak at $1665 \mathrm{~cm}^{-1}(\mathrm{p} 3)$. The integrated areas of the peaks were calculated by the Microcal Origin $7.5^{\circledR}$ (Microcal Software, Inc., Northampton, MA, USA).

\subsection{Statistical analysis}

The measurements obtained from the integrated area under the Raman peaks (p1-p5) were statistically analyzed using Instat software (GraphPad Software, Inc., San Diego, CA, USA). The one-way ANOVA test at a 95\% confidence level and the Tukey-Kramer multiple comparisons test were applied to test the significance of the relative area evaluation between the normal and supplement bone data. Statistical analyses were initially performed using the difference between normal and treated values of the relative area. Comparisons between the groups were also performed considering only the treated values.

\section{Results and discussion}

Figure 2 presents the Raman spectral profile of creatine, being that Fig. 3 demonstrates the carbonate/phosphate ratio of the control group as well as of the groups treated with creatine supplements. It is possible to infer that the relative concentration of carbonate in the bones decreased significantly with a higher ingestion of creatine by the animals. However, it is interesting to note that the carbonate/phosphate ratio is higher to the animals treated with supplement that has higher quantity of creatine, allowing to infer that the absorption of creatine is not directly proportional to the creatine quantity administrated to the individuals. Possibly, the influence of creatine ingestion in the carbonate/phosphate ratio is limited, 


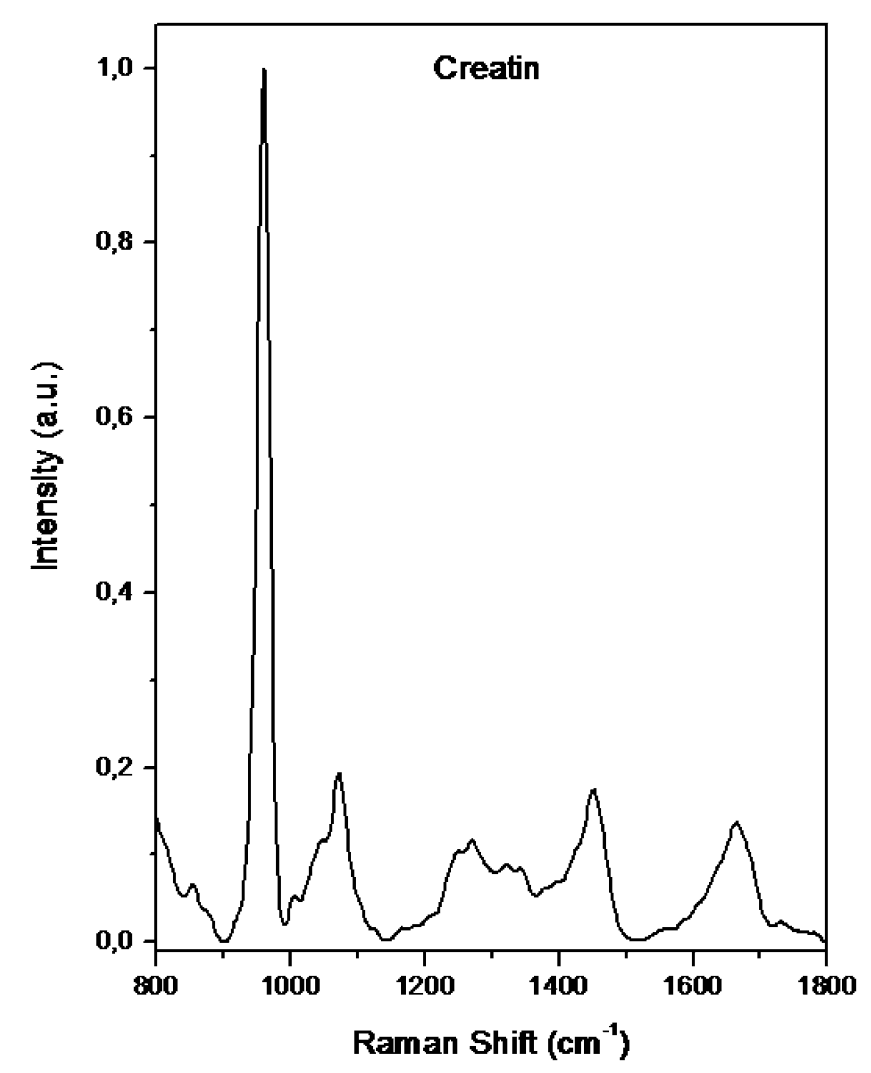

Fig. 2. Raman spectral profile of creatine.

\section{Carbonate/Phosphate Ratio}

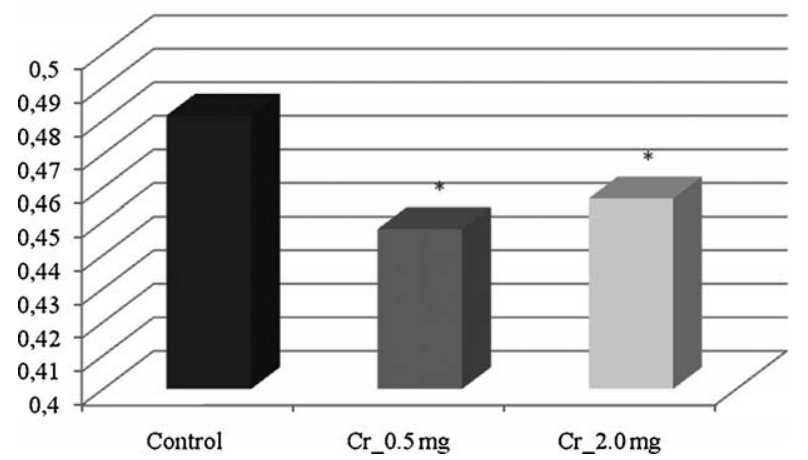

Fig. 3. * Significant difference $(p<0.05)$ for control group; control - control group; Cr_0.5 mg - supplemented with creatine $0.5 \mathrm{~g} / \mathrm{kg}$ group; Cr_2.0 mg - supplemented with creatine $2.0 \mathrm{~g} / \mathrm{kg}$ group.

being that $0.5 \mathrm{~g} / \mathrm{kg}$ would represent an optimum administration in order to promote a more effective repercussion in the bones.

Figure 4 demonstrates that the relative concentration of phosphate has a slight increase with nutrition supplemented with creatine $0.5 \mathrm{~g} / \mathrm{kg}$, while the relative presence of phosphate in animals that received creatine $2.0 \mathrm{~g} / \mathrm{kg}$ is practically the same of the control group (a very small decrease). This data reinforce 


\section{Phosphate:Amide I Ratio}

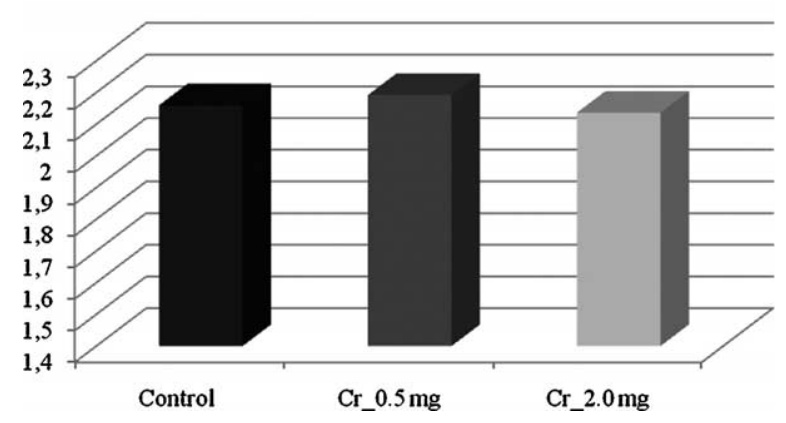

Fig. 4. Control - control group; Cr_0.5 mg - supplemented with creatine $0.5 \mathrm{~g} / \mathrm{kg}$ group; Cr_2.0 mg - supplemented with creatine $2.0 \mathrm{~g} / \mathrm{kg}$ group.

\section{Carbonate:Amide I Ratio}

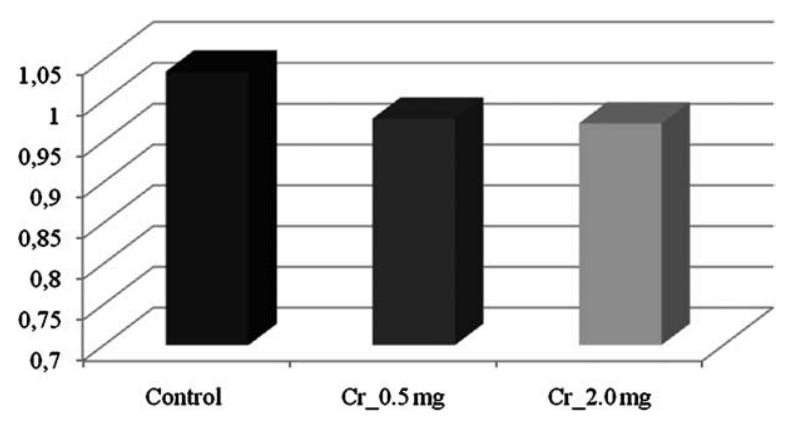

Fig. 5. Control - control group; Cr_0.5 mg - supplemented with creatine $0.5 \mathrm{~g} / \mathrm{kg}$ group; Cr_2.0 mg - supplemented with creatine $2.0 \mathrm{~g} / \mathrm{kg}$ group.

the analysis related to the Fig. 3. In fact, this apparently contradictory result could be associated to two factors. Firstly, the excessive creatine supplement administration would generate an opposite effect as function of a biochemical reaction of the organism, i.e., the physiological response to the supplement excess would increase significantly the metabolism of creatine, implying in a practically insignificant effect on the bone constitution. In this way, the excessive creatine supplementation does not seem to affect representatively the phosphate concentration in bones. A second factor could also be associated to the results obtained in the present work. In fact, considering the data presented in Fig. 3, the experimental data, indirectly, suggest that the decrease in the carbonate/phosphate ratio could also be related by a significant decrease in the carbonate concentration in the bones.

Figure 5 presents the relative concentration of carbonate to the amide groups showing that the control group presents a higher relative concentration of carbonate in relation to the amide groups, when compared with the two groups with alimentation enriched with creatine supplementation. This results corroborates the proposal inferred from the analysis of Fig. 4 that the decrease in carbonate/phosphate ratio is also provoked by the carbonate decrease and not only by the increase of phosphate concentration.

The analysis of the present data allows to infer that Raman spectroscopy is a suitable instrumental tool in order to be applied in the analysis of chemical constitution evaluation of bones. Actually, the well established assignment of Raman peaks permits a very sensitive study, involving qualitative and quantitative determinations. This potential can be identified firstly through the significant isolation between 
the Raman signals assigned to each group evaluated in the present work. In fact, the attribution of the vibrational peaks of interest in the bone evaluation involves wavelengths quite different, i.e., mutually separated peaks. In this way, it is possible a complete investigation around all Raman peaks related to the chemical composition of the bones.

\section{Conclusions}

The present data strongly suggest that creatine supplementation needs to be controlated in order to promote effective results on the bone constitution. Indeed, an excessive administration would not generate a higher presence of phosphate in the bones, in opposite of an limited administration of creatine. Moreover, the ingestion of creatine supplement tends to decrease the relative presence of carbonate in the chemical constitution of bones, which can be associated to a significantly altered bone resistance to several mammalians. Furthermore, this fact can be associated to a more intense metabolism, which can alter the carbonate concentration as function of several biochemical processes.

The present article is a very original contribution focused on the biomedical applications of Raman spectroscopy, especially involving the influence of alimentation on the constitution of bones. Probably, this high sensitivity can be employed to determine spectral profiles, such as wavelength of maximum absorption and maximum intensity of absorption of each wavelength, of several bone diseases.

\section{References}

[1] A. Antolic, B.D. Roy, M.A. Tarnopolsky, R.F. Zernicke, G.R. Wohl, S.G. Shaughnessy and J.M. Bourgeois, Creatine monohydrate increases bone mineral density in young Sprague-Dawley rats, Med. Sci. Sports Exerc. 39 (2007), 816-820.

[2] A. Brose, G. Parise and M.A. Tarnopolsky, Creatine supplementation enhances isometric strength and body composition improvements following strength exercise training in older adults, J. Gerontol. A Biol. Sci. Med. Sci. 58 (2003), 11-19.

[3] A. Carden and M.D. Morris, Application of vibrational spectroscopy to the study of mineralized tissues (review), J. Biomed. Opt. 5 (2000), 259-268.

[4] J.L.C. Ch'ng and B. Ibrahim, Transcriptional and posttranscriptional mechanisms modulate creatine kinase expression during differentiation of osteoblastic cells, J. Biol. Chem. 269 (1994), 2336-2341.

[5] D. Cleveland, M. Carlson, E.D. Hudspeth, L.E. Quattrochi, K.L. Batchler, S.A. Balram, S. Hong and R.G. Michel, Raman spectroscopy for the undergraduate teaching laboratory: Quantification of ethanol concentration in consumer alcoholic beverages and qualitative identification of marine diesels using a miniature Raman spectrometer, Spectrosc. Lett. 40 (2007), 903-924.

[6] P. Daniel, P. Picart, L. Bendriaa, G.D. Sockalingum, I. Adt, T. Charrier, M.J. Durand, F. Ergan, M. Manfait and G. Thouand, Effects of toxic organotin compounds on bacteria investigated by micro-Raman spectroscopy, Spectrosc. Lett. 41 (2008), 19-28.

[7] E.R. Draper, M.D. Morris, N.P. Camacho, P. Matousek, M. Towrie, A.W. Parker and A.E. Goodship, Novel assessment of bone using time-resolved transcutaneous Raman spectroscopy, J. Bone Miner. Res. 20 (2005), 1968-1972.

[8] J.J. Freeman, B. Wopenka, M.J. Silva and J.D. Pasteris, Raman spectroscopic detection of changes in bioapatite in mouse femora as a function of age and in vitro fluoride treatment, Calcified Tissue Int. 68 (2001), 156-162.

[9] V. Funanage, P. Carango, I.M. Shapiro, T. Tokouka and R.S. Tuan, Creatine kinase activity is required for mineral deposition and matrix synthesis in endochondral growth cartilage, Bone Miner. 17 (1992), 228-236.

[10] S.J. Gadeleta, A.L. Boskey, E. Paschalis, C. Carlson, F. Menschik and T.A. Baldini, A physical, chemical, and mechanical study of lumbar vertebrae from normal, ovariectomized and nandrolone decanoate-treated cynomolgus monkeys (Macaca fascicularis), Bone 27 (2000), 541-550.

[11] I. Gerber, I. Ap Gwynn, M. Alini and T. Wallimann, Stimulatory effects of creatine on metabolic activity, differentiation and mineralization of primary osteoblast-like cells in monolayer and micromass cell cultures, Eur. Cell Mater. 10 (2005), 8-22.

[12] P.L. Greenhaff, The creatine-phosphocreatine system: there's more than one song in its repertoire, J. Physiol. 537(3) (2001), 657. 
[13] E.B. Hanlon, R. Manoharan, T.W. Koo, K.E. Shafer, J.T. Motz, M. Fitzmaurice, J.R. Kramer, I. Itzkan, R.R. Dasari and M.S. Feld, Prospects for in vivo Raman spectroscopy, Phys. Med. Biol. 45 (2000), R1-R59.

[14] G.M. Hobson, V.L. Funanage, J. Elsemore, M. Yagami, R. Rajpurohit, J.C. Perriard, N.J. Hickok, I.M. Shapiro and R.S. Tuan, Developmental expression of creatine kinase isoenzymes in chicken growth cartilage, J. Bone Miner. Res. 14 (1999), 747-756.

[15] M. Izquierdo, J. Ibanez, J.J. Gonzalez-Badillo and E.M. Gorostiaga, Effects of creatine supplementation on muscle power, endurance, and sprint performance, Med. Sci. Sports Exerc. 34 (2002), 332-343.

[16] A.P.W. Johnston, D.G. Burke, L.G. MacNeil and D.G. Candow, Effect of creatine supplementation during cast-induced immobilization on the preservation of muscle mass, strength, and endurance, J. Strength Cond. Res. 23 (2009), 116-120.

[17] H. Katoh, T. Kojima, S. Okushiba, E. Shimozawa and T. Tanabe, Bleeding esophageal varices associated with pancreatic arteriovenous malformation, World J. Surg. 15 (1991), 57-60.

[18] A.C.-T. Ko, L.-P. Choo-Smith, M. Hewko, L. Leonardi, M.G. Sowa, C.C.S. Dong, P. Williams and B. Cleghorn, Ex vivo detection and characterization of early dental caries by optical coherence tomography and Raman spectroscopy, J. Biomed. Opt. 10 (2005), 1-16.

[19] Y. Liu and C.Y. Hsu, Laser-induced compositional changes on enamel: A FT-Raman study, J. Dent. 35 (2007), $226-230$.

[20] C.B. Lopes, A.L. Pinheiro, S. Sathaiah, J. Duarte and C.M. Martins, Infrared laser light reduces loading time of dental implants: a Raman spectroscopic study, Photomed. Laser Surg. 23 (2005), 27-31.

[21] C.B. Lopes, M.T. Pacheco, L. Silveira Jr., J. Duarte, M.C. Cangussú and A.L. Pinheiro, The effect of the association of NIR laser therapy BMPs, and guided bone regeneration on tibial fractures treated with wire osteosynthesis: Raman spectroscopy study, J. Photochem. Photobiol. B 89 (2007), 125-130.

[22] B.R. McCreadie, M.D. Morris, T.C. Chen, D. Sudhaker Rao, W.F. Finney, E. Widjaja and S.A. Goldstein, Bone tissue compositional differences in women with and without osteoporotic fracture, Bone 39 (2006), 1190-1195.

[23] S. Mihic, J.R. MacDonald, S. McKenzie and M.A. Tarnopolsky, Acute creatine loading increases fat-free mass, but does not affect blood pressure, plasma creatinine, or CK activity in men and women, Med. Sci. Sports Exerc. 32 (2000), 291296.

[24] L.M. Moreira, L. Silveira Jr., F.V. Santos, J.P. Lyon, R. Rocha, R. Zângaro, A.B. Villaverde and M.T.T. Pacheco, Raman spectroscopy: a powerful technique for biochemical analysis and diagnosis, Spectroscopy - Ottawa 22 (2008), 1-19.

[25] G.V. Nogueira, A.A. Martin, R.A. Zângaro, M.T.T. Pacheco, M.C. Chavantes and C.A. Pasqualucci, Raman spectroscopy study of atherosclerosis in human carotid artery, J. Biomed. Opt. 10 (2005), 031117/1-031117/7.

[26] A.P. Oliveira, R.A. Bitar, L. Silveira, R.A. Zângaro and A.A. Martin, Near-infrared Raman spectroscopy for oral carcinoma diagnosis, Photomed. Laser Surg. 24 (2006), 348-353.

[27] S. Pilotto, M.T.T. Pacheco, L. Silveira Jr., A.B. Villaverde and R.A. Zângaro, Analysis of near-infrared Raman spectroscopy as a new technique for a transcutaneous non-invasive diagnosis of blood components, Lasers Med. Sci. 16 (2001), 2-9.

[28] J.G. Ramasamy and O. Akkus, Local variations in the micromechanical properties of mouse femur: the involvement of collagen fiber orientation and mineralization, J. Biomech. 40 (2007), 910-918.

[29] E.S. Rawson and J.S. Volek, Effects of creatine supplementation and resistance training on muscle strength and weightlifting performance, J. Strength Cond. Res. 17 (2003), 822-831.

[30] J.M. Reyes-Goddard, H. Barr and N. Stone, Photodiagnosis using Raman and surface enhanced Raman scattering of bodily fluids, Photodiagn. Photodyn. Ther. 2 (2005), 223-233.

[31] G.K. Sakkas, K. Mulligan, M. DaSilva, J.W. Doyle, H. Khatami, T. Schleich, J.A. Kent-Braun and M. Schambelan, Creatine fails to augment the benefits from resistance training in patients with HIV infection: a randomized, double-blind, placebo-controlled study, PLOS ONE 4(2) (2009), e4605.

[32] L. Silveira Jr., S. Sathaiah, R.A. Zângaro, M.T.T. Pacheco, M.C. Chavantes and C.A. Pasqualucci, Near infrared Raman spectroscopy of human coronary arteries: histopathological classification based on Mahalanobis distance, J. Clin. Laser Med. Surg. 21 (2003), 203-208.

[33] B. Swinson, W. Jerjes, M. El-Maaytah, P. Norris and C. Hopper, Optical techniques in diagnosis of head and neck malignancy, Oral Oncol. 42 (2006), 221-228.

[34] M.A. Tarnopolsky and D.P. Maclennan, Creatine monohydrate supplementation enhances high-intensity exercise performance in males and females, Int. J. Sport Nutr. Exerc. Metab. 10 (2000), 452-463.

[35] J.A. Timlin, A. Carden and M.D. Morris, Chemical microstructure of cortical bone probe by Raman transects, Appl. Spectrosc. 53 (1999), 1429-1435.

[36] H. Tsuda, J. Ruben and J. Arends, Raman spectra of human dentine mineral, Eur. J. Oral Sci. 104 (1996), 123-131.

[37] T. Wallimann and W. Hemmer, Creatine kinase in non-muscle tissues and cells, Mol. Cell. Biochem. 133,134 (1994), 193-220.

[38] M. Wyss and R. Kaddurah-Daouk, Creatine and creatinine metabolism, Physiol. Rev. 80 (2000), 1107-1213.

[39] J.S. Yerramshetty and O. Akkus, The associations between mineral crystallinity and the mechanical properties of human cortical bone, Bone 42 (2008), 476-482. 
[40] H. Yuan, Z. Yang, Y. Li, X. Zhang, J.D. Bruijn and K. Groot, Osteoinduction by calcium phosphate biomaterials, J. Mater. Sci.: Mater. Med. 9 (1998), 723-726.

[41] H. Zeng, A. McWilliams and S. Lam, Optical spectroscopy and imaging for early lung cancer detection: a review, Photodiagn. Photodyn. Ther. 1 (2004), 111-122. 


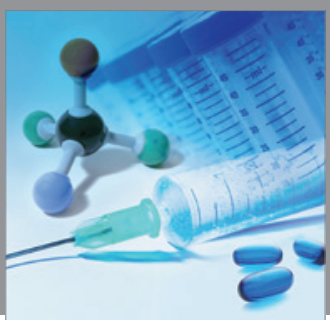

International Journal of

Medicinal Chemistry

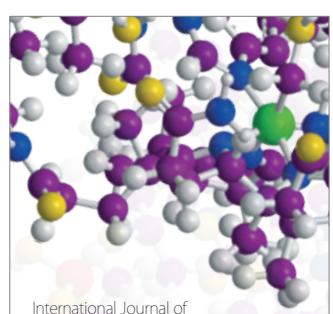

Carbohydrate Chemistry

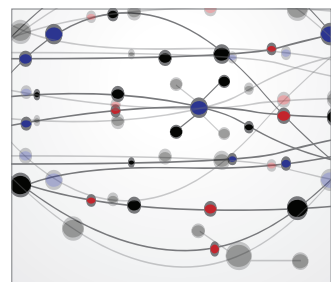

The Scientific World Journal
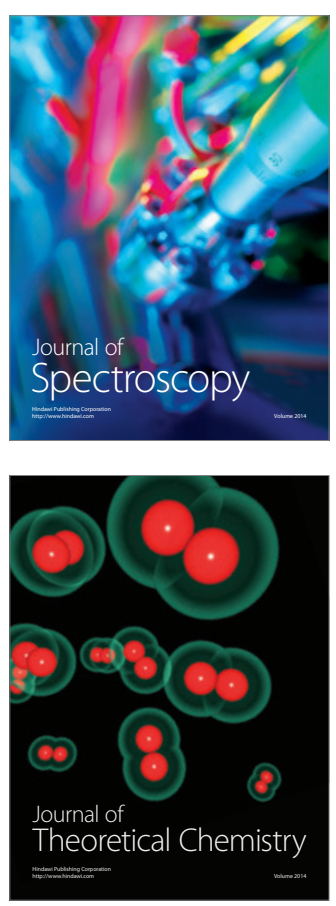
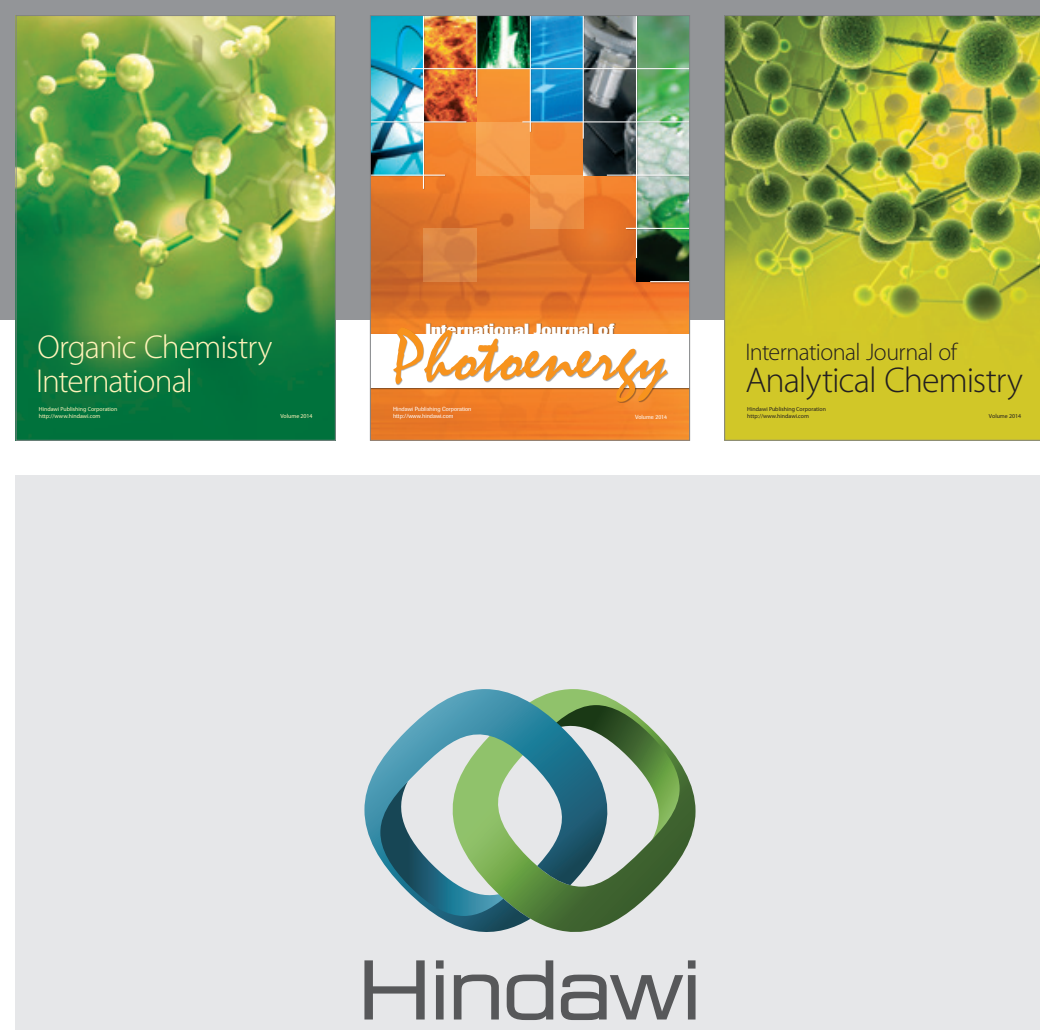

Submit your manuscripts at

http://www.hindawi.com
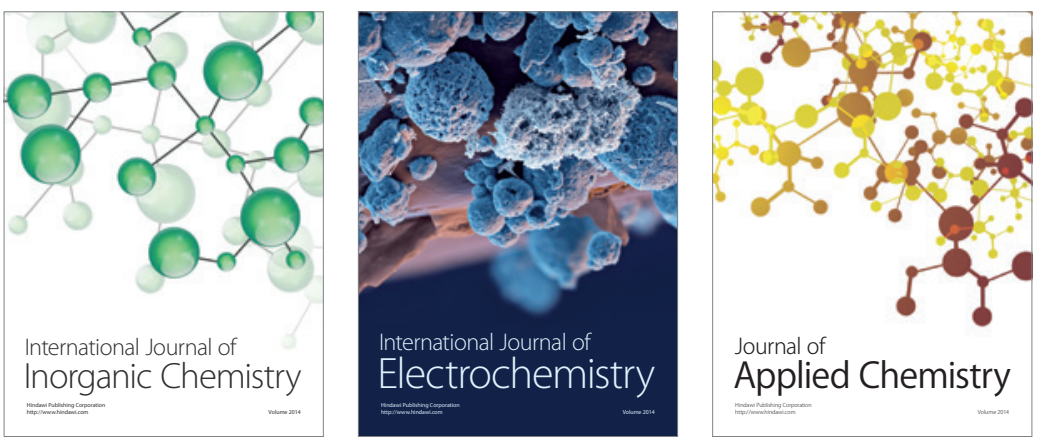

Journal of

Applied Chemistry
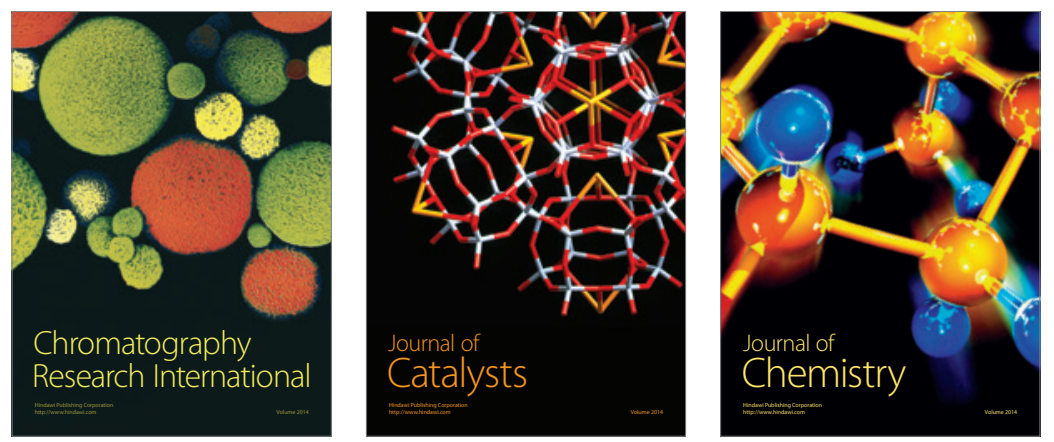
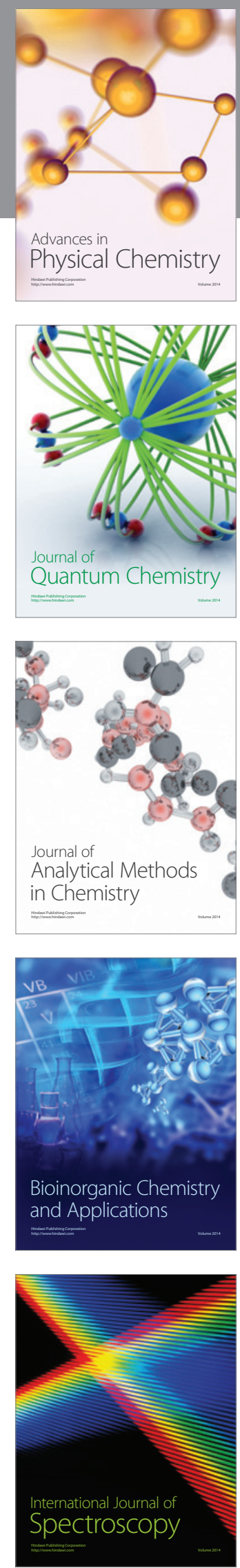